\title{
The Impact of Knowledge Management Processes on Organisational Performance
}

\author{
Mohammed Tubigi, Information Systems Evaluation and Integration Network Group \\ (ISEing) Brunel Business School, Brunel University, UK. \\ mohammed.tubigi@brunel.ac.uk
}

Sarmad N. Alshawi, Information System Evaluation and Integration Network Group

(ISEing) Brunel Business School, Brunel University, UK.

Sarmad.alshawi@brunel.ac.uk

\begin{abstract}
In today's increasingly competitive business environment, the use of knowledge to gain a competitive advantage has become a serious concern for all organisations. However, despite the increasing number of studies relating to Knowledge Management (KM) in developed countries, few studies have explored this issue within the context of developing countries. Moreover, some industries have been affected more acutely than others in the transition to a knowledge-based economy. Towards covering this gap, this study aims at investigating the impact of Knowledge Management processes on Organisational Performance (OP). In this paper, the authors propose a conceptual model through an in-depth investigation of the previous and current studies in the area of Knowledge Management and Organisational Performance. Through an extensive classification of Knowledge Management processes, the proposed model explores the impact of each Knowledge Management process on improving the level of Organisational Performance. It is envisaged that this model can play a role in guiding the process of Knowledge Management implementation in order to maximise the beneficial effects of Knowledge Management processes on Organisational Performance.
\end{abstract}

Keywords: Knowledge, Knowledge management processes, Organisational performance.

\section{Introduction}

Within the current economic climate, organisations are facing many difficulties and challenges due to a multiplicity of factors such as globalisation and the resulting intensification of competition between organisations. This situation is encouraging the use of new management concepts and paradigms such as $\mathrm{KM}$ that have been recognised as an important tool for improving the efficiency and success of organisations (Lee and Choi, 2003).

Most of the available studies relating to $\mathrm{KM}$ have considered organisational knowledge as a significant asset for gaining competitive advantage and as a significant contributor to the success and survival of any organisation within a highly competitive business environment (e.g. Zack et al, 2009; Marqués \& Simón, 2006; Hasan \& Al-Hawari, 2003 and Claycomb et al, 2002). Subsequently, investigation of some aspects of KM (mainly KM processes) is viewed as an imperative issue for intensive research. As a result of this, effective implementation of KM processes has become a key strategy for improving OP since suitable management and application of knowledge can assist 
organisations to be more creative, intelligent and better able to adapt to an ever changing business climate (Wong and Aspinwall, 2004).

Indeed, $\mathrm{KM}$ can be seen as a strategy that assists organisations to use knowledge to envisage, make and control the whole decision making process (Kongpichayanond, 2009). Furthermore, enhancing and cultivating the individual knowledge of members of an organisation is a clear strategy for developing a continuous organisational learning that can lead to better performance (Nonaka, 1998; O'Dell and Grayson, 1998). However, despite the potential benefits that can be gained from utilising $\mathrm{KM}$ in the workplace and relatively the large number of studies relating to KM concept, there have been a limited number of studies analysing the ways in which OP can be influenced by KM and here comes the main contribution of this analytical study through proposing an applicable conceptual model for the interaction between a comprehensive set of KM processes and a set of OP measurements. To this end, this study seeks to provide an in-depth examination into the practices and implications of KM within a specific socio-cultural context. This will potentially enables the development of a conceptual model for KM implementation that can improve the performance of organisations.

The proposed conceptual model requires an empirical validation, which will be performed by authors in next stage of this study. The overall importance of this research is derived from the importance of $\mathrm{KM}$ as a strategic organisational tool as well as the potential impact of KM processes on the organisational overall performance

\section{Methodology}

The main approach of this paper is to conduct a comprehensive literature review in order to build a theoretical platform to first understand KM processes and effectively enhance these processes and maximise their positive impact on organisational performance as the most important concern for business organisations. The literature review presented in this paper begins by defining and evaluating the concepts of knowledge and its management, knowledge management processes, organisational performance, knowledge management processes and organisational performance, and knowledge management processes impact on organisational performance as found in the literature, choosing specific, albeit holistic, concepts for utilisation by this study. The review then examines the findings of a selection of the literature in terms of the relationship between KM and OP. The limitations of the previous research will then be addressed to identify the gap in the current literature and accordingly the conceptual framework in which this study seeks to present.

\section{Knowledge and its Management}

"Understanding of what constitutes knowledge is central to its effective management" (Pathirage, Amaratunga and Haigh, 2007, p.116). However, knowledge itself has suffered from severe definitional issues. Grey (1996) postulated that knowledge is the full usage of information and data, together with the potential of ideas, commitment and motivation, people's skills, competencies, and intuitions. However, knowledge could be defined as a human process of justifying personal belief towards reality (Nonaka and Takeuchi, 1995). Nevertheless, these two definitions stress the involvement of human beings and as Beveren (2002,p.19) asserts "even though some argue knowledge can be acquired, stored and used outside of the human brain, knowledge cannot exist outside of the human brain and that only information and data can exist outside of the brain'. It is clear therefore that KM goes far beyond the management of information and data but must necessarily involve the information contained within the minds of the firm's employees.

Knowledge is an invisible and intangible asset and thus difficult to be measured or managed by traditional parameters (Al-adaileh and Al-atawi, 2011). Therefore, management of knowledge is also 
more comprehensive than the simple management of information. Whilst information can be stored outside the human brain, the primary part of an organisation's knowledge is located within the minds of its members (Al-adaileh and Al-atawi, 2011; Marques and Simon, 2006). If we accept knowledge to be socially constructed then, like culture, it emerges and develops through organic creation and societal interaction. Knowledge is thus seen in terms of cognitive, situational, experiential and emotional factors (Al-adaileh and Al-atawi, 2011). Effective utilisation of organisational knowledge in a way that adds value to the organisational knowledge is referred to within the academic literature as 'KM'. However, one could argue that the concept of knowledge is so subjective that its meaning differs among scholars and that every organisation has its own definition of knowledge, how it should be gathered, categorised and made available to employees (e.g. Zaim, 2006; Marques and Simon, 2006; Nonaka, 1994).

Depending on which view of knowledge is adopted, the focus of KM must be different. According to Alavi and Leidner (2001) if knowledge is viewed as a process, then the implied KM focus is on the knowledge flow and the processes of creating, sharing, and distributing knowledge, if knowledge is viewed as an object, then KM should focus upon the building and managing of knowledge stocks. If we are to understand the importance of tacit knowledge, as scholars such as Nonaka would argue, then any KM practices must prioritise the conversion of this knowledge into explicit knowledge and its management as tacit knowledge through social interaction. In spite of the fact that KM has become an important line of research in the last few years, it is still difficult to find a conceptualisation that is commonly accepted by a majority. This is unsurprising given that knowledge is, in itself, both a tangible and intangible resource (Hall, 1993). Marques and Simon (2006) do, however, conclude that the following set of practices can be considered as aspects of KM:

- Orientation towards the development, transfer and protection of knowledge;

- Continuous learning in the organisation;

- An understanding of the organisation as an overall system;

- Development of an innovative culture to encourage $R \& D$ projects;

- Approach based on individuals; and

- Competence development and management based on competences

Marques and Simon (2006: p 144)

\section{Knowledge Management Processes}

Effective utilisation of organisational knowledge in a way that adds value to the organisational knowledge is referred to within the academic literature as 'KM'. Yang and Wan (2004) provide a comprehensive view of the concept of KM that manages to identify all of the processes involved. They define $\mathrm{KM}$ as "the process of collecting and identifying useful information (i.e. knowledge acquisition), transferring tacit knowledge to explicit knowledge (i.e. knowledge creation or transfer), storing the knowledge in the repository (i.e. organisational memory), disseminating it through the whole organisation (i.e. knowledge sharing), enabling employees to easily retrieve it (i.e. knowledge retrieval) and exploiting and usefully applying knowledge (i.e. knowledge leverage)"

(Yang and Wan, 2004, p.595).

KM processes might be defined as the processes by which individuals, teams and organisational subsystems interact, create, store, share, and effectively use knowledge. An effective organisational environment and the implementation of (KM) processes should increase the quality as well as quantity of both explicit and tacit knowledge of individuals, teams and the whole organisation (Sanchez and Palacios, 2008.).

Nonaka (1994) also asserts that knowledge is fundamentally convertible and proposed four key stages of knowledge conversion known as SECI (socialisation, externalisation, combination and internalisation). Nonaka and Takeuchi (1995) postulated that knowledge conversion involves the 
transformation of tacit into explicit knowledge followed by the re-transformation from explicit into tacit knowledge. They described the following KM processes:

- Socialisation which is seen as the method of adapting implicit knowledge into new tacit knowledge.

- Externalisation which involves the process of articulating tacit knowledge into explicit knowledge.

- Combination which is seen as the method of transferring explicit knowledge into more intricate and organised sets of explicit knowledge.

- Internalisation is the process of integrating explicit knowledge into tacit knowledge.

According to Nonaka (1994), knowledge conversion processes within the context of large organisations can be seen as mechanisms to create knowledge through continuous dialogue on tacit and explicit knowledge. This, as one could argue, can limit the value of these processes to the measurement of knowledge creation which is seen by other researchers as one of the main KM processes. However, it is not the only one that should be considered as of value.

A more comprehensive view of the constituent KM processes is provided by Zaim (2006) who claims that it is possible to compose a more comprehensive process-oriented view of $\mathrm{KM}$. He stated that: "KM is the systematic management of all activities and processes referred to generation and development, codification and storage, transferring and sharing, and utilisation of knowledge for an organisation's competitive edge" (Zaim, 2006, p.3). Process-oriented definition of KM was also emphasised by Jashapara (2004) who revealed that KM involves any practice or process of acquiring, creating, sharing, capturing and using knowledge, wherever it resides, to enhance organisations learning and performance.

In fact, researchers differ in terms of their appreciation of KM processes and different researches have adopted different processes of KM. Table 1 below provides a summary of some of these processes.

Table 1: Summary of KM processes

\begin{tabular}{|l|l|}
\hline Author & Processes \\
\hline Alavi and Leidner (2001) & Knowledge creation, knowledge sharing, knowledge distribution. \\
\hline De Jarnett (1996) & $\begin{array}{l}\text { Knowledge construction, knowledge embodiment, knowledge dissemination and } \\
\text { use, knowledge retention and refinement. }\end{array}$ \\
\hline Fong and Choi (2009) & $\begin{array}{l}\text { Knowledge acquisition, knowledge creation, knowledge storage, knowledge } \\
\text { distribution, knowledge use, knowledge maintaining. }\end{array}$ \\
\hline Lettieri et al (2004) & $\begin{array}{l}\text { KM cycle in non-profit organisation, storage, retrieval, diffusion and presentation, } \\
\text { application, creation }\end{array}$ \\
\hline Mills and Smith (2011) & Knowledge creation, knowledge acquisition. \\
\hline Mishra and Bhaskar (2011) & Knowledge creation. \\
\hline Quintas et al (1997) & Process or practice of crating, acquiring, capturing, sharing, and using knowledge \\
\hline Singh and Soltani (2010) & Knowledge creation, knowledge use, knowledge transfer. \\
\hline Zack et al (2009) & Knowledge location and sharing; Knowledge experimental and creation. \\
\hline Zaim et al (2007) & $\begin{array}{l}\text { Knowledge generation and development; knowledge codification and storage; } \\
\text { knowledge transfer and sharing; and knowledge utilization. }\end{array}$ \\
\hline Zolingen et al (2001) & $\begin{array}{l}\text { Acquiring knowledge, establishing knowledge, disseminating knowledge, } \\
\text { developing knowledge, applying knowledge }\end{array}$ \\
\hline Yang and Wang (2004) & Knowledge acquisition. \\
\hline
\end{tabular}




\section{Organisational Performance}

For every scholar or practitioner within business and management disciplines, performance is the paramount concern (Politis, 2002). Chakravarthy (1986) argued that it is difficult to engage in comprehensive comparative analysis of the differences between the performances of companies when using traditional financial measures such as Return on Equity (ROE), Return on Capital (ROC), and Return on Sales (ROS). Similarly, Kaplan and Norton (1996) found that classic financial accounting measures such as Return on Investment (ROI) and Earning Per Share (EPS) can be deceptive when providing indications regarding the issues of continuous progress and innovation. This suggests that these traditional accounting practices with their focus on short-term indicators such as share prices, turn over, cash flow and profit are not actually appropriate for assessing the overall performance of corporations, whereas non-financial elements such as stakeholders, investors and customers have recently been recognised as more accurate indicators (Edvinsson, 1997; Lee, Lee and Kang, 2005).

In addition to the definitional difficulties mentioned above, in order to measure the impact of KM on OP, scholars must establish a means by which OP should be measured. This is more problematic than it might appear since the changing nature of the 'firm' or 'organisation' has led to a corresponding need to adjust the scales and factors by which we measure performance. It is also important to be able to utilise a method of measurement which is compatible with the independent variable (Knowledge Management). This is because it has proven to be problematic to measure the effects of KM when utilising more traditional measurements for evaluating firm performance. For instance, Tanriverdi (2005) only found a moderately weak relationship ( $\mathrm{r} 1 / 40.15$ to 0.17 ) between a firm's financial performance (ROA and Tobin's Q) and its ability to create, share, integrate, and use knowledge. As Davenport (1999) show that, although the relationship between KM and performance indicators has been discussed at length of balance sheet, exchange value, market value, etc, few firms have been able to create a causal relationship between KM activities and OP utilising traditional measurements. Many scholars have therefore felt it necessary to attempt to measure other OP indicators when attempting to investigate the effects of $\mathrm{KM}$ including non-financial performance measures such as productivity (Lapre and Wassenhove, 2001), quality (Mukherjee, Lapre, and Wassenhove, 1998), and innovation (Francisco and Guadamillas, 2002). Cotora (2007) claimed that to measure corporate performance, it is imperative that a system takes into account indefinable values such as competencies, partnerships and knowledge along with inter-relationships and the process of conversion in situations.

In order to consider financial and non-financial measures, Maltz, Shenhar and Reilly (2003) have developed performance model, called Dynamic Multi-dimensional Performance (DMP) framework which has also empirically tested its validity to modern organisation. The DMP model consists of five major success dimension namely (financial, market, process, people, and future). This research project shall adopt these five performance measures proposed by Maltz, Shenhar and Reilly (2003) to evaluate the organisational performance as they provide a holistic approach to measuring organisational success and are comprehensive and clear in their identification of measurement tools.

\subsection{Knowledge Management Processes and Organisational Performance}

One of the main difficulties that the vast majority of the literature faces and attempts to deal with in this field is that of how to measure the relationship between two holistic and intangible concepts (KM and FP) (Decarolis and Deeds, 1999; Davenport, 1999). The main issue for scholars dealing with the area of KM is attempting to examine the ways in which it affects OP. In order for KM as a discipline to be accepted as of as great importance as its proponents would argue, it is necessary to be able to demonstrate a clear and causal link between effective Knowledge Management within an organisation and an improvement in that organisation's performance.

Many scholars and practitioners have simply taken the apparent tautology for granted (Kalling, 2003) since successful firms utilise more and better knowledge than others. However, the "conversion of knowledge into improved performance is not automatic or free from problems" (Kalling, 2003, p.68). Whilst common sense might indicate that such a relationship must exist and that any firm which improves its knowledge management practices would thereby see an improvement in performance, 
both proving that link empirically and designing a theory that is capable of explaining, reasoning and predicting the relationship between the two has proven problematic.

It must be noted that there is a significant gap in the literature of "large-scale empirical evidence that KM makes a difference to organisational performance" (Zack, McKeen, and Singh, 2009, p.393). This has translated into problems for practitioners. For example, in a survey of 431 US and European organisations by the Ernst \& Young Centre for Business Innovation, the most difficult obstacle faced in carrying out KM practices was found to be "measuring the value of knowledge assets and/or impact of knowledge management” (Ruggles, 1998,p.82).

The indicators show that there is a positive relationship between an efficient and effective application of KM and organisational performance such as Hasan and Al-Hawari (2003) and Claycomb, Droge and Germain (2002). Perceived benefits of KM can range from better knowledge sharing, cost savings, faster access to knowledge, increased profitability, and shorter time-to-market to new business opportunities (Skyrme, 2001). Marqués and Simón, (2006) explored the connection between KM practices and organisational performance based on an empirical study carried out on 222 Spanish firms in the biotechnology and telecommunications industries. Their study revealed how the organisations that adopt knowledge management practices obtain better results than their competitors.

Yang and Wang (2004) examined the extent to which the four International five-star hotels in Taiwan implement KM practices (notable the acquiring, sharing and storing), the method in which they are implemented and the impediments they face. The study shows that KM practices, such as programs and cultures that support knowledge sharing, storing, and acquiring, can benefit such hotels not only financially but in terms of the functioning of the organisation and welfare of the staff.

Furthermore, Darroch (2005) provides empirical evidence to support the role of KM practices within organisations based on the analysis of data that was collected from CEOs representing organisations with 50 or more employees from a cross-section of industries; the study presents knowledge management as a coordinating mechanism. This empirical evidence supports the view that an organisation with a knowledge management capability will use resources more efficiently and so will be more innovative and perform better. In addition, according to the study, knowledge acquisition positively affected both knowledge dissemination and responsiveness to knowledge. Similarly, knowledge dissemination was found to have positively affected responsiveness to knowledge. Thus, an organisation with access to a greater pool of knowledge is likely to have better developed knowledge dissemination and responsiveness to knowledge behaviours and practices. Likewise, an organisation with better-developed knowledge dissemination behaviours and practices is likely to be more responsive to knowledge. It is clear from this study that not only do KM practices improve OP, they also enhance each other.

It is also argued that KM provides continuous learning for better business performance and accelerates the spiral of innovation. (Chang and Ahn, 2005). Consequently, it can be postulated that with successful implementation of KM practice, organisations are able to perform intelligently to sustain their competitive advantage by developing their knowledge assets (Wiig, 1999).

However, many of the studies drew quite nuanced conclusions. For instance, Darroch $(2005$, p.107) found that "firms with well developed knowledge management practices and behaviours are more likely to develop incremental innovations", but that there was "insufficient evidence to support the view that firms with well developed knowledge management practices and behaviours will perform better", (Darroch, 2005, p.107) and that, out of the indicators examined only responsiveness to knowledge was found to directly influence organisational performance.

Furthermore, Zack, McKeen and Singh, (2009) investigated the organisational impact of KM in terms of performance. Twelve KM practices were identified and explored in terms of their impact on organisational performance within the context of business organisation in North America and Australia. The study revealed that KM practices were directly related to organisational performance 
which, in turn, was directly related to financial performance. On the other hand, there was no direct relationship found between KM practices and financial performance.

Tanriverdi (2005) found only a weak correlation between a firm's use of knowledge and its financial performance. In addition, due to the extremely large number of exogenous factors, such linkage is obscure and difficult to be empirically validated (Bharadwaj, 2000). Therefore, many studies suggest more immediate indicators of KM performance such as level of knowledge sharing (Bock and Kim, 2002), knowledge quality (Huang, Lee and Wang 1999).

Indeed, this lack of ability to directly relate OP and $\mathrm{KM}$ in enough correlation has led many to extrapolate from the relationships they are able to evaluate positively. For instance Lee and Choi (2003) concluded that as long as KM practices enhance aspects of organisational performance, positive financial performance will later result. They found direct relationship between KM practices and various intermediate measures of strategic organisational performance namely; product leadership, operational excellence, and customer intimacy, which in turn are associated with financial performance.

To provide more in-depth into the investigation of the previous studies relating to the impact of KM processes on organisational performance, table 2 summarises some of the previous studies that were relevant to the focus of this research.

Table 2: summary of previous studies concerning the interrelationship between KM Processes and Organisational Performance

\begin{tabular}{|c|c|c|c|}
\hline Article & Nature of study & $\begin{array}{l}\text { Study } \\
\text { method }\end{array}$ & Key finding(s) \\
\hline $\begin{array}{l}\text { Claycomb, Droge and } \\
\text { Germain (2002) }\end{array}$ & Empirical & Survey & $\begin{array}{l}\text { There is a general consensus that knowledge } \\
\text { and performance are positively and } \\
\text { significantly related }\end{array}$ \\
\hline Daud, and Yusoff (2010) & Empirical & Survey & $\begin{array}{l}\text { The results based on } 289 \text { questionnaires } \\
\text { revealed both that KM processes influence } \\
\text { social capital positively and that social capital } \\
\text { enhances organisational performance. The } \\
\text { study emphasised that KM processes and } \\
\text { social capital can be integrated to enhance } \\
\text { organisational performance }\end{array}$ \\
\hline $\begin{array}{l}\text { Gold, Malhotra and Segars } \\
\text { (2001) }\end{array}$ & Empirical & Survey & $\begin{array}{l}\text { Knowledge infrastructure capabilities and } \\
\text { knowledge processes capabilities impact } \\
\text { organisational performance }\end{array}$ \\
\hline Hasan and Al-Hawari (2003) & Empirical & $\begin{array}{l}\text { Case } \\
\text { Study }\end{array}$ & $\begin{array}{l}\text { They indicate that there is a positive } \\
\text { relationship between an efficient and effective } \\
\text { application of KM and organisational } \\
\text { performance }\end{array}$ \\
\hline Kalling (2003) & Empirical & $\begin{array}{l}\text { Case } \\
\text { Study }\end{array}$ & $\begin{array}{l}\text { The effect of KM on organisational } \\
\text { performance is contingent on various firm } \\
\text { level and organisational level contingencies. } \\
\text { KM is divided into three processes - } \\
\text { knowledge development, knowledge } \\
\text { utilisation and knowledge capitalisation. Each } \\
\text { process has its own contingencies factors and } \\
\text { performance outcomes }\end{array}$ \\
\hline Mills and Smith (2011) & Empirical & Survey & $\begin{array}{l}\text { The results show that some knowledge } \\
\text { resources (e.g. organisational structure, } \\
\text { knowledge application) are directly related to } \\
\text { organisational performance, while others (e.g. } \\
\text { technology, knowledge conversion), though } \\
\text { important preconditions for knowledge }\end{array}$ \\
\hline
\end{tabular}




\begin{tabular}{|l|l|l|l|}
\hline & & & $\begin{array}{l}\text { management, are not directly related to } \\
\text { organisational performance }\end{array}$ \\
\hline Moorthy and Polley (2010) & Empirical & $\begin{array}{l}\text { Case } \\
\text { Study }\end{array}$ & $\begin{array}{l}\text { Their results revealed that an analysis of the } \\
\text { depth and breadth of technological knowledge } \\
\text { contribute significantly more towards } \\
\text { predicting measures of organisational } \\
\text { performance such as return on invested capital, } \\
\text { sales growth, and Tobin's q }\end{array}$ \\
\hline Zaim (2006) & Empirical & Survey & $\begin{array}{l}\text { This study revealed that there is a positive } \\
\text { relationship between KM processes and KM } \\
\text { performance }\end{array}$ \\
\hline
\end{tabular}

\subsection{Knowledge Management Processes Impact on Organisational Performance}

Since knowledge is rapidly becoming a very important measure of the organisational future performance (Choi and Lee, 2002), it is therefore vital that indictors and measurement techniques are developed in order to allow managers to handle the organisational knowledge better. The contribution which $\mathrm{KM}$ can make is an important issue for research especially given the increasing emphasis on the concept of knowledge workers and the knowledge based organisation. Moreover, KM has the potential to help organisations to select, organise, capture, distribute, and transfer significant information, knowledge, and expertise which enables improvement of organisational performance.

Much research has highlighted the importance of knowledge in company performance, and organisations are increasingly concerned with managing their knowledge effectively to keep ahead of the competition. Yet, according to Kalling (2003), current research into KM does not identify or offer a clear understanding of the role of KM in improving organisation's performance. Many scholars have tried to assess KM's contribution such as Su, Chen and Sha (2006), who claim that knowledge work can lead to new technologies to develop new products and ways of working. Moreover, the knowledge base of a company is commonly viewed as the fundamental underlying factor in performance levels (Lai and Lee, 2007). For numerous scholars (Amit and Schoemaker, 1993; Grant, 1996; Krogh and Roos, 1996; Spender, 1996; Teece, 2000; Eisenhardt and Santos, 2002) knowledge, which possesses all kind of strategic asset, is the paramount and the only resource for achieving sustainable higher performance.

Bergeron (2003) provides probably the most detailed and, for the purposes of this study, useful description of KM processes. He used the concept of KM life cycle including eight processes (creation and acquisition, modification, use, transfer, archiving, translating/repurposing, access, and disposal). This research will adopt these eight processes to evaluate KM life cycle processes.

\subsubsection{Knowledge creation and acquisition}

Knowledge creation, when defined as a process, refers to the initiatives and activities undertaken towards the generation of new ideas or objects (Mitchell and Boyle, 2010). It is organisation's ability to develop new ideas and solutions regarding different aspects of organisational activities, from managerial practices to products to technological processes (e.g.Nonaka, 1991, Un and CuervoCazurra, 2004). According to Mills and Smith (2011), the term "acquisition"' refers to a firm's ability to identify, acquire and accumulate knowledge (whether internal or external) that is essential to its operations. The external sources for an organisation to acquire knowledge could be through hiring people possessing the required knowledge or by purchasing knowledge assets such as patents, research documents or other intelligence (Wong and Aspinwall, 2004). In the creation and acquisition phase of the KMLC, information is created or acquired internally by knowledge workers, externally through outsourcing, or purchased from an outside source, and the mechanisms for this phase including self-reporting, documentation, program, instrumentation, network, knowledge engineering (Bergeron, 2003). To this end therefore, according to the previous studies and Bergeron (2003) concept of KM life cycle it is expected that: 
- Knowledge creation and acquisition is positively related to organisational performance through self-reporting, documentation, program instrumentation, networks, and knowledge engineering.

\subsubsection{Knowledge Modification}

Bhatt (2001) stated that modification or conversion process takes place along the supply chain of data, information and knowledge, he argued that organisations must speedily convert data into information, and this information into organisational knowledge to maximise benefits from this process. According to Bergeron (2003) the information through the modification phase is modified to meets the requirements of the future needs of the knowledge management and their workers, the support mechanisms of this phase include editing tools, tracking, security, and version control. To this end therefore, according to the previous studies and Bergeron (2003) concept of KM life cycle it is expected that:

- Knowledge modification is positively related to organisational performance through editing tools, tracking, security, and version control.

\subsubsection{Knowledge Use}

The information is employed for whichever purpose necessary based on the situation. The range of potential uses for information is virtually unlimited depending upon the needs and activities of the knowledge workers and management within the organisation (Bergeron, 2003). Knowledge that an employee fails to use or share is of little importance to an organisation. Bhatt (2001) stated that making knowledge more active and relevant for the organisation in creating values depends on applying and sharing this knowledge. The ultimate goal for knowledge is to get the right knowledge to the right people at the right time and to help people share and use different types of knowledge to improve organisational performance. In fact, one could argue that the real value of all KM processes comes from the effective use of individual and organisational collective knowledge. Employees should collaborate to use knowledge for the benefits of their organisations through acquire, accumulate, seek, create, generate and capture knowledge (Daud and Yusoff, 2010). Bergeron (2003) stated that the support mechanisms for this phase are feedback system, tracking system, dissemination technology, and search technologies. To this end therefore, according to the previous studies and Bergeron (2003) concept of KM life cycle it is expected that:

- Knowledge use is positively related to organisational performance through feedback systems, tracking systems, dissemination technology, and search technologies.

\subsubsection{Knowledge Archiving}

Archiving involves the storing of the information in an appropriate form that ensures the security and access to this information in the future, and this happen through information technologies, controlled vocabularies, librarian, controlled environment, and maintenance programs (Bergeron, 2003). An organisation is constantly in danger of accidentally losing the gained knowledge if this knowledge that has been acquired, created and shared, not supported by knowledge storage and documentation (Stein and Swass, 1995). As stated by Alavi and Leidner( 2001) the organisational memory resides in various forms such as electronic databases, written documents, codified knowledge in expert systems, organisational procedures and processes, and tacit knowledge located in individuals brain. To this end therefore, according to the previous studies and Bergeron (2003) concept of KM life cycle it is expected that:

- Knowledge archiving is positively related to organisational performance through information technologies, controlled vocabularies, librarian, controlled environment, and maintenance programs.

\subsubsection{Knowledge Transfer}

Knowledge transfer was defined as: "a process of exchange of explicit or tacit knowledge between two agents, during which one agent purposefully receives and uses the knowledge provided by 
another", "Agent" can refer to an individual, a team, an organisational unit, the organisation itself or a cluster of organisations (Kumar and Ganesh,2009, p.163). Argote and Ingram (2000, p.151) define knowledge transfer as "the process through which one unit (e.g., group, department, or division) is affected by the experience of another". Knowledge transfer is about connection that ultimately depends on choice made by individuals (Dougherty, 1999). Bergeron (2003) postulated in order to increase the value of the information and to enable knowledge sharing, information should be transferred freely within the organisational context using various types of media (e.g. entrant, emails). $\mathrm{He}$ assumed that in this phase physical transfer, and networks are the support mechanisms. To this end therefore, according to the previous studies and Bergeron (2003) concept of KM life cycle it is expected that:

- Knowledge transfer is positively related to organisational performance through physical transfer, and networks.

\subsubsection{Knowledge Translation/Repurposing}

In this phase the information might be translated from its original form into a form that is more suitable for the user (e.g. from numerical to textual form), this is important to simplify the information in order to suit the recipient's specific requirements and their own knowledge base, and this process take place through outsource expertise, and information technologies (Bergeron, 2003). To this end therefore, according to the previous studies and Bergeron (2003) concept of KM life cycle it is expected that:

- Knowledge translation/repurposing is positively related to organisational performance through outsource expertise, and information technologies.

\subsubsection{Knowledge Access}

Bergeron (2003) show that successful KM systems should provide continuous access for authorised users through the use of query support mechanisms. A parallel access should also be available and supported by the system. Lettieri, Borga and Savoldelli (2004) make the points that knowledge distribution can be accessible to whoever can use it. Furthermore, different kind of people (e.g. managers, professionals, client, etc) perhaps could need to show the information in different ways depending on how they have to use (Lettieri, Borga and Savoldelli, 2004). In fact, the value of knowledge is restricted with the ability to access it when needed to make decisions or to solve organisational problems or for whatever purpose in any given situation. The support mechanisms for this phase are corporate policy, information technology, and librarian (Bergeron, 2003). To this end therefore, according to the previous studies and Bergeron (2003) concept of KM life cycle it is expected that:

- Knowledge access is positively related to organisational performance through corporate policy, information technologies, and librarian.

\subsubsection{Knowledge Disposal}

Some information will be of little or no value in the future and therefore should be destroyed or stored elsewhere through established processes and technologies in order to keep the standard body of knowledge at a level which is manageable (Bergeron, 2003). Clear, coherent procedures should be applied when selecting information for disposal or disposing them in order that valuable information does not end up being destroyed. To this end therefore, according to the previous studies and Bergeron (2003) concept of KM life cycle it is expected that:

- Knowledge disposal is positively related to organisational performance through established processes, and technologies. 


\section{Conceptual Model}

Based on the previous discussion, the following conceptual research model was proposed as a platform for exploration of the influential relationship between a set of KM processes (creation and acquisition, modification, use, transfer, archiving, translating/repurposing, access, and disposal) and OP. The first eight arrows represent the Knowledge Management Processes Life Cycle and its relationship to Organisational Performance.

\section{Figure 1: Research Conceptual Model}

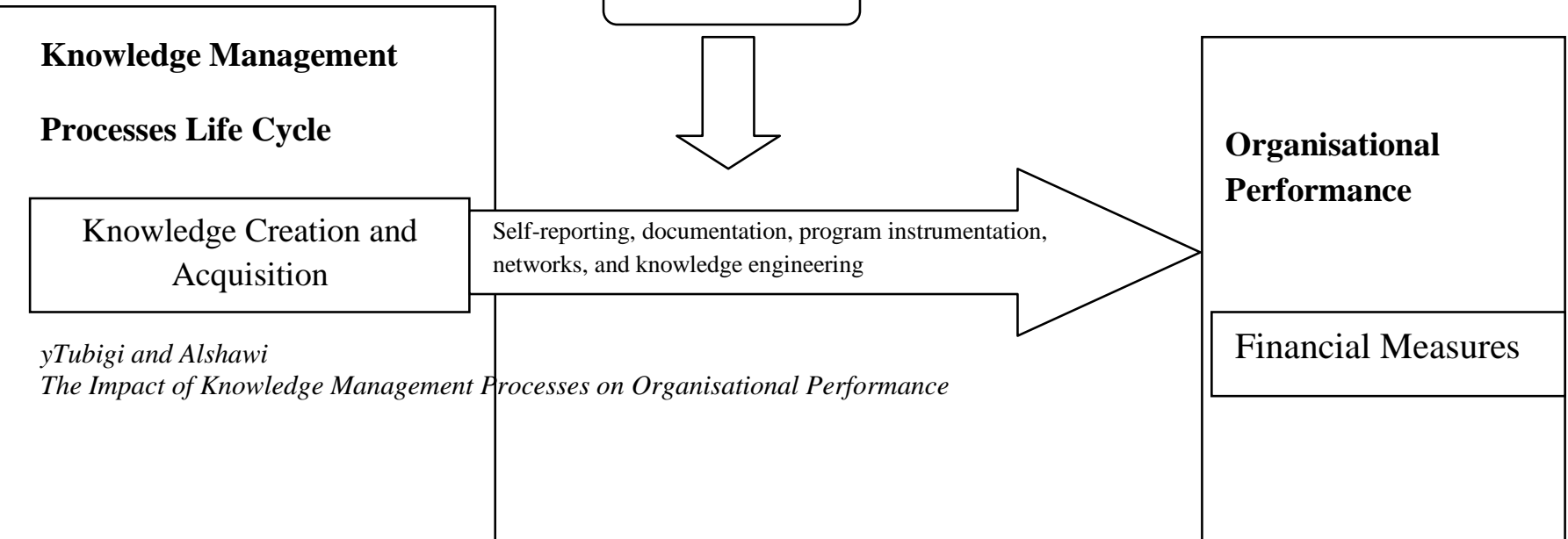




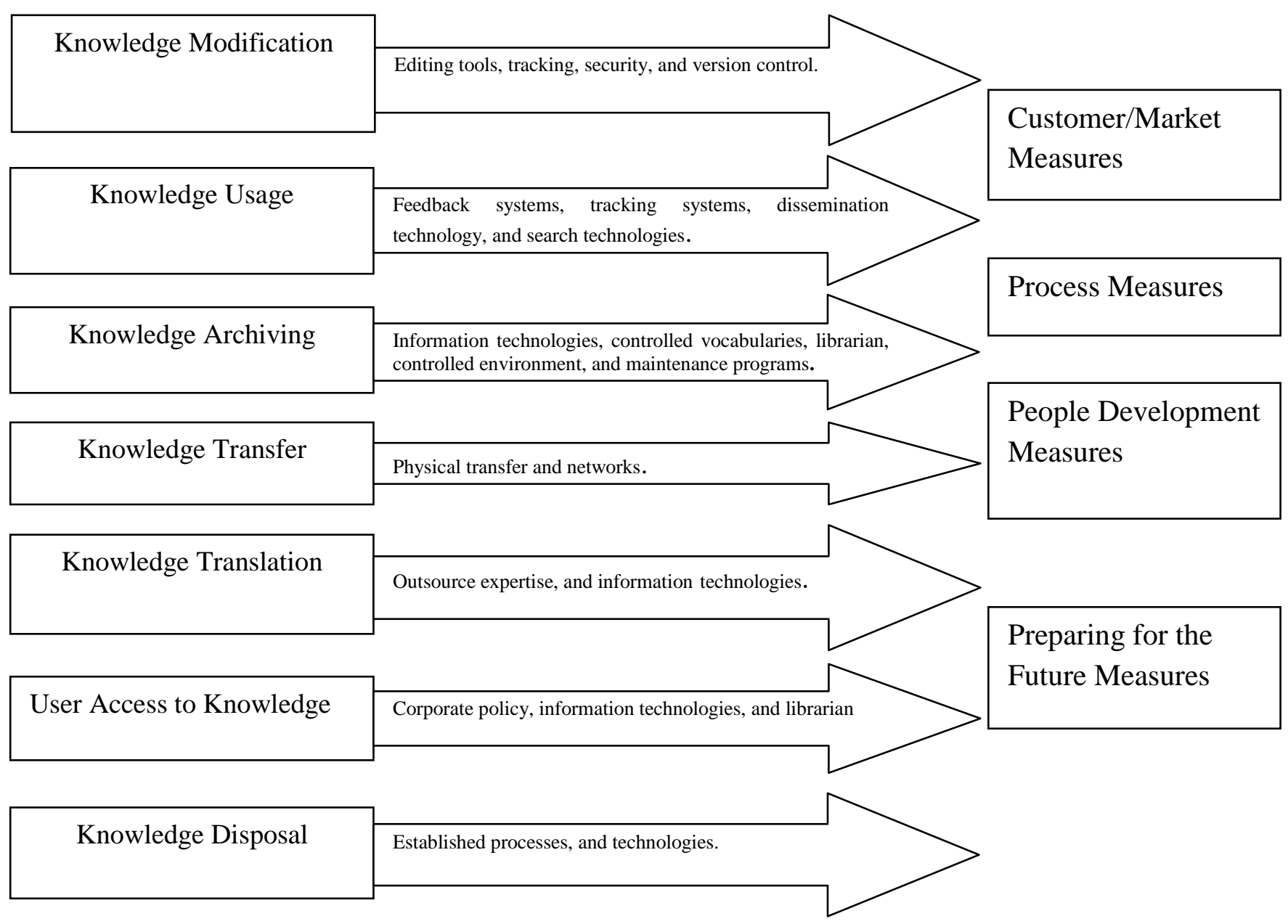

\section{Conclusion}

This paper presented an analytical review of the available studies concerning the interrelationship between KM processes and OP. The study provides analysis of the KM processes and revealed a state of disagreement among the researchers not only concerning the processes involved within the KM concept but also the impact of these processes on OP. This study has identified eight KM processes namely knowledge creation and acquisition, knowledge modification, knowledge usage, knowledge archiving, knowledge transfer, knowledge translation/repurposing, user access knowledge, and knowledge disposal that are seen as comprehensive processes representing the valuable aspects of organisational knowledge. These processes have also been adopted by Bergeron (2003). However, comparing with other KM processes that were identified by other scholars and researchers, this study concludes that Bergeron's classification is the most comprehensive. Accordingly, the next empirical stage of this research will use these KM processes and attempts to measure their impact on OP which might lead to more in-depth validation of these proposed processes as well as providing a guideline for effective utilisation of these processes to improve OP.

\section{Future Work}

This study is interested in investigating the impact of knowledge management processes on organisational performance, issues and difficulties, and important factors and seeing their views and perceptions on knowledge management. Thus, case study method which involves a single organisation or group of organisational units is both appropriate methods for this study. Primary data will be collected through both field study and pilot study which will be use to develop and test the conceptual model, interview will be use for this purpose, and the formal field research will be use a 
combination of research techniques such as personal interviews (face-to-face interviews)- semistructure interviews will be conducted with top, middle managers which will enable us to ask the same questions to different respondents, the documentary analysis will investigate different kind of documents and reports from inside and outside the organisations relevant to the study problem.

\section{References}

Ackroyd D and Hughes J.A. 1992. 'Data collection in context'. London: Longman.

Al-adaileh R. 2008. 'Essentials of management information systems'.Karak-Jordan: YazeedPublications.

Al-Adaileh R and Al-Atawi M. 2011. 'Organisational culture impact on knowledge exchange: Saudi Telecom context'. Journal of Knowledge Management, 15 (2): 212-230.

Alavi M and Leidner D. 2001. 'Review: knowledge management and knowledge management systems: conceptual foundations and research issues'. MIS Quarterly, 25(1): 107-136.

Amit R and Schoemaker P.J.H. 1993. 'Strategic Assets and Organisational Rent'. Strategic Management Journal, 14(1): 33-46.

Argote L and Ingram P. 2000.'Knowledge transfer: a basis for competitive advantage in firms'. Organisational Behaviour and Human Decision Processes, 82 (1): 150-169.

Bergeron B. 2003. 'Essentials of knowledge management'. Hoboken, New Jersey: John Wiley $\&$ Sons, Inc.

Beveren J.V. 2002. 'A model of knowledge that refocuses knowledge management'. Journal of knowledge management, 6 (1): 18-22.

Bharadwaj A.S. 2000. 'A resource-based perspective on information technology capability and firm performance: an empirical investigation'. MIS Quarterly, 24 (1):169-196.

Bhatt G.D. 2001. 'Knowledge management in organisations: examining the interaction between technologies, techniques, and people'. Journal of knowledge management, 5(1): 68-75.

Bock G.W and Kim Y.G. 2002. 'Breaking the myths of rewards: an exploratory study of attitudes about knowledge sharing'. Information resource management journal, 15 (2):14-21.

Chakravarthy B.S.1986. 'Measuring strategic performance'. Strategic management, 7 (5):437-458.

Chang S and Ahn J. 2005. 'Product and process knowledge in the performance-oriented knowledge management approach'. Journal of Knowledge Management, 9 (4):114-132.

Choi B and Lee H. 2002.'Knowledge management strategy and its link to knowledge creation process'. Expert Systems with Applications, 23(3):173-187.

Claycomb C, Droge C and Germain R. 2002.'Applied product quality knowledge and performance'. International Journal of Quality \& Reliability Management, 19(6): 649-671.

Cotora L. 2007. 'Managing and measuring the intangibles to tangibles value flows and conversion process: romanian space agency case study'. Measuring business excellence, 11(1): 53-60.

Darroch J. 2005.'Knowledge management: innovation and firm performance'. Journal of Knowledge Management, 9 (3):101-115.

Davenport T. 1999.'Knowledge management and the broader firm: Strategy, advantage, and performance'. In Liebowitz, J. (eds) Knowledge Management Handbook.CRC Press: Boca Raton, 1-11.

Davenport T.H and Prusak L. 1998. 'Working knowledge. Boston: Harvard Business School Press.

Daud S and Yusoff W. 2010. 'Knowledge management and firm performance in SMEs: the role of social capital as a mediating variable', Asian Academy of Management Journal, 15 (2):135-155.

DeCarolis D.M and Deeds D.S. 1999.'The impact of stocks and flows of organisational knowledge on firm performance: an empirical investigation of the biotechnology industry'. Strategic Management Journal, 20 (10):953-968.

De Jarnett L. 1996.'Knowledge the latest thing: information strategy'. The Executives Journal, 12 (2):3-5.

Dougherty V.1999. 'Knowledge is about people, not databases'. Industrial and Commercial training, 
$31(7): 262-266$.

Drucker P. 2001. 'The next society: a survey of the near future'. The Economist, 3 (1):2-20.

Edvinsson L. 1997. 'Developing intellectual capital at skandia'. Long Range Planning, 30 (3):366-373.

Eisenhardt K.M and Santos F.M. 2002. 'Knowledge-based view: a new theory of strategy?'. in:

Pettigrew A, Thomas H and Whittington R (Ed) Handbook of strategy and management, London: Sage publications:139-164.

Fong P.S.W and Choi S.K.Y. 2009. 'The processes of knowledge management in professional services firms in the construction industry: a critical assessment of both theory and practice'. Journal of Knowledge Management, 13 (2):110-126.

Fontana A and Frey F.H. 1998. 'Interviewing the art of science in denzil, N.K. and Lincoln, Y.S. (eds): Collecting and Interpreting Qualitative Materials, London: Sage.

Francisco J.F and Guadamillas F. 2002. 'A case study on the implementation of knowledge management strategy oriented to innovation'. Knowledge and Process Management, 9 (3): 162671.

Ghauri P, Gronhaugh K and Kristianslund I. 1995. 'Research methods in business studies-a practical Guide'. New York: Prentice Hall.

Gold A.H, Malhotra A and Segars A. 2001. 'Knowledge management: an organisational capabilities perspective'. Journal of Management Information Systems, 18 (1):185-214.

Grant R.M. 1996. 'Toward a knowledge-based theory of the firm'. Strategic management journal, 17, winter special issue pp. 109-122

Grey D. 1996. 'What is knowledge? : The knowledge management forum. Available at: http://www.km-forum.org/what is.htm [Accessed 25th January 2012].

Hall R.1993. 'A framework linking intangible resources and capabilities to sustainable competitive advantage'. Strategic Management Journal, 14 (8):607-618.

Hasan H and Al-Hawari M. 2003. 'Managing styles and performance: a knowledge space framework'. Journal of Knowledge Management, 7 (4):15-28.

Huang K.T, Lee, Y.L and Wang R.W.1999. 'Quality information and knowledge'. New Jersey: Prentice Hall PTR.

Jashapara A.2004. 'Knowledge management: an integral approach'. Harlow, England: Financial Times Prentice Hall.

Kalling T. 2003. 'Knowledge management and the occasional links with performance'. Journal of Knowledge Management, 7 (3):67-81.

Kaplan R.S and Norton D.P. 1996. 'The balanced scorecard'. Boston: Harvard Business School Press.

Kongpichayanond P. 2009. 'Knowledge management for sustained competitive advantage in mergers and acquisitions'. Advances in developing human resources, 11 (3):375-387.

Krogh G and Roos J. 1996. 'Managing knowledge: perspectives on cooperation and competition'. London: Sage Publication.

Kumar J and Ganesh L.S. 2009. 'Research on knowledge transfer in organisations: a morphology'. Journal of Knowledge Management, 13 (4): 161-174.

Lai M.F and Lee G.G. 2007. 'Relationship of organisational culture toward knowledge activities'. Business Process Management Journal, 13 (2):306-322.

Lapr M.A and Wassenhove L.N.V.2001. 'Creating and transferring knowledge for productivity improvement in factories'. Management Science, 47 (10):1311-1325.

Lee H and Choi B. 2003. 'Knowledge management enablers, Processes, and organisational performance: an integrative view and empirical examination processes, and organisational'. Journal of Management Information System, 20 (1):179-228.

Lee K.C, Lee S and Kang I.W. 2005. 'KMPI: Measuring knowledge management performance'. Information \& Management, 42 (3):469-482.

Leidner D and Alavi M.. 2006. 'The role of culture in knowledge management :a case study of two global firms'. International Journal of E-Collaboration, 2 (1):17-40.

Lettieri E, Borga F and Savoldelli A. 2004. 'Knowledge management in non-profit Organisations'. Journal of Knowledge Management, 8 (6):16-30.

Maltz A.C. Shenhar A.J and Reilly R.R. 2003. 'Beyond the balanced scorecard: refining the search for organisational success measures'. Long Range Planning, 36 (2):187-204.

Marques D and Simon F. 2006. 'The effect of knowledge management on firm performance'. Journal 
of Knowledge Management, 10 (3):143-156.

Mills A and Smith T. 2011. 'Knowledge management and organisational performance, a decomposed view'. Journal of Knowledge Management, 15 (1): 156-171.

Mishra B and Bhaskar A. 2011. 'Knowledge management process in two learning organisations', Journal of Knowledge Management, 15 (2): 344-359.

Mitchell R and Boyle B. 2010. 'Knowledge creation measurement methods', Journal of Knowledge Management, 14 (1): 67-82.

Moorthy S and Polley D. 2010. 'Technological knowledge breadth and depth: performance impacts', Journal of Knowledge Management, 14 (3): 359-377.

Mukherjee A.S Lapre M.A and Wassenhove L.N.V. 1998. 'Knowledge driven quality improvement', Management Science, 44 (11): S35-S49.

Nonaka I. 1994. 'A dynamic theory of organisational knowledge creation', Organisation Science, 5 (1): $14-37$.

Nonaka I and Takeuchi H.1995. The knowledge-creating company: how Japanese companies create the dynamics of innovation. Oxford: Oxford University Press.

Nonaka I.1998. The knowledge-creating company. Boston: Harvard Business School Press.

O'Dell C and Grayson C. J. 1998. If only we knew what we know. Identification and transfer of internal best practices. New York: Free Press.

Pathirage C ,Amaratunga D and Haigh R. 2007. 'Tacit knowledge and organisational performance: construction industry perspective'. Journal of Knowledge Management, 11 (1): 115-126.

Politis J.D. 2002. 'Transformational and transactional leadership enabling (disabling) knowledge acquisition of self-managed teams: the consequences for performance'. The Leadership and Organisational Development Journal, 23 (4): 186-197.

Quintas P, Lefrere H and Jones G.1997. 'Knowledge management: a strategic agenda'. Long Range Planning, 30 (3): 385-391.

Ruggles R.L.1998. 'The state of notion: knowledge management in practice'. California Management Review, 40 (3): 80-89.

Sanchez M.P.S and Palacios M.A. 2008. 'Knowledge-based manufacturing enterprises: evidence from a case study'. Journal of Manufacturing Technology Management, 19 (4): 447-468.

Schein E.H. 2004. Organisational culture and leadership. 3rd edn. New York: John Wiley \& Sons.

Sherif K, Hoffman J and Thomas B. 2006. 'Can technology build organisational social capital? : The case of a global IT consulting firm'. Information \& Management, 43 (7):795-804.

Singh A and Soltani E.2010. 'Knowledge management practices in Indian information technology companies'. Total Quality Management, 21 (2):145-157.

Skyrme D.J. 2001. Capitalizing on knowledge: from E-Commerce to K-Commerce. Massachusetts, USA: Butterworth-Heinemann Newton.

Spender J.C. 1996. 'Making knowledge the basis of a dynamic theory of the firm'. Strategic Management Journal, 17 (10): 45-62.

Stein E.W and Swass V.1995. 'Actualizing organisational memory with information systems', Information Systems Research, 6 (2): 85-117.

Su C.T Chen Y.H and Sha D.Y. 2006. 'Linking innovative product development with customer knowledge: a data-mining approach'. Technovation, 26 (7): 784-795.

Tanriverdi H. 2005. 'Information technology relatedness, knowledge management capability, and performance of multi-business firms'. MIS Quarterly, 29 (2): 311-334.

Teece D.J. 2000. Managing intellectual capital. Oxford: Oxford University Press.

Un C.A and Cuervo-Cazurra A. 2004. 'Strategies for knowledge creation in firms'. British Journal of Management, 15 (S1):27-41.

Wiig K.M. 1999.'Introducing knowledge management into the enterprise', in Liebowitz, J. (Ed.) Knowledge management handbook. Boca Raton, FL. CRC Press LLC.

Wong K.Y and Aspinwall E. 2004. 'Characterizing knowledge management in the small business environment', Journal of Knowledge Management, 8 (3): 44-61.

Wong K.Y and Aspinwall E. 2006. 'Development of a knowledge management initiative and system: a case study'. Expert Systems with Applications, 30 (40): 1-9.

Yang $\mathrm{J}$ and Wang C. 2004. 'Advancing organisational effectiveness and knowledge management 
implementation'. Tourism Management, 25 (5): 593-601.

Yin R. K. 1994. 'Case study research: design and methods'. Beverly Hills: Sage.

Yin R. K. 2003. 'Case study research: design and methods'. $3^{\text {rd }}$ edition, Thousand Oaks, CA: Sage

Zack M, McKeen J and Singh S. 2009. 'Knowledge management and organisational performance: an exploratory analysis'. Journal of Knowledge Management, 13 (6): 392-409.

Zaim H. 2006. 'Knowledge management implementation in IZGAZ', Journal of Economic and Social Research, 8 (2): 1-25.

Zaim H, Tatoglu E and Zaim S. 2007. 'Performance of knowledge management practices: a causal analysis'. Journal of Knowledge Management, 11 (6): 54-67.

Zolingen S.V, Streumer J.N and Stooker M. 2001. 'Problems in knowledge management: a case study of knowledge-intensive company'. International Journal of Training and Development, 5 (3): 168-184. 